\title{
Patterns on the Embroidered Textiles Unearthed from the Silk Road II : Geometrical Pattern
}

\author{
Kuang Yanghua ${ }^{1} \&$ Cui Rongrong ${ }^{1}$ \\ ${ }^{1}$ Jiangsu Intangible Cultural Heritage Research Base, Textile \& Clothing College, Jiangnan University, Jiangsu, \\ China \\ Correspondence: Kuang Yanghua, Jiangsu Intangible Cultural Heritage Research Base, Textile \& Clothing \\ College, Jiangnan University, 1800 Lihu Avenue, Wuxi, Jiangsu Province, 214122, China. Tel: \\ 86-139-2110-1775. E-mail: tinakyh2005@aliyun.com
}

Received: September 9, 2015 Accepted: September 30, 2015 Online Published: December 21, 2015

doi:10.5539/ass.v12n1p191

URL: http://dx.doi.org/10.5539/ass.v12n1p191

\begin{abstract}
Based on the archaeological evidences from the Silk Road, this paper reviews geometrical pattern on the embroidered textiles of the Han and Tang dynasties (2ndC BC-early 9thC AD). The evidences show that geometrical pattern is mainly found on textiles from Northwestern China rather than Central China. Although not widely available, it is characterized by its varied types. The regular geometrical patterns on the embroidered textiles from the Silk Road include dots, roundels, waves, whorls, triangles, diamonds, lozenges, chevrons, zigzags and crosses. As the most common motif, dots not only intersperse with other patterns or form lines as edgings but also create frames of various kinds such as roundels, diamonds and hexagons etc. then filled with other patterns. Diamonds are also common, besides serving as pattern they are often used as frames. In addition, there are examples consisting of more than one type of geometrical patterns.
\end{abstract}

Keywords: geometrical patterns, embroidery, the Silk Road

Geometrical pattern is another common motif on embroidered textiles unearthed from the graveyards or ancient sites along the Silk Road, especially on the embroideries dating from the Han and Jin dynasties (2ndC BC-early 4thC AD) unearthed from Xinjiang province and the embroidered textiles of the Northern Wei dynasty (late 3thC- early 5thC) from Dulan or neighboring areas in Qinghai province now in the collection of China National Silk Museum. They are varied in types.

\section{Dots}

Table 1. Dots on the embroidered textiles unearthed from the Silk Road

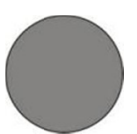

Figure 1. dots on embroideries from Astana, Yinpan, Huahai etc., 2ndC BC-early 4thC AD

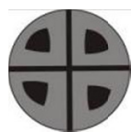

Figure 2. dots on embroideries from

Dulan or neighboring areas, late 3 thC- early 5 thC

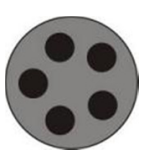

Figure 3. dots on embroideries from

Dulan or neighboring areas, late 3 thC- early 5 thC

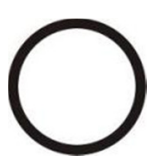

Figure 4. dots on embroideries from

Dulan or neighboring areas, late 3 thC-early 5 thC

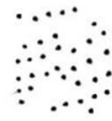

Figure 5. dots on an embroidery from Noin-Ula, late 1stC BC-early $1 \mathrm{stC} A D$

Dots are common to see on the embroidered textiles of the Han and Jin dynasties unearthed from the Silk Road, among which dots filled with volute stitches executed in chain stitch or split stitch (Figure 1 in Table 1) are particularly popular and widely appear on the embroidered textiles from Shanpula, Niya, Yingpan, Lop-Nor, Murtuq, Astana in Xinjiang province and Huahai in Gansu province, especially on the embroideries from Astana. There are other types of dots, including dots filled with a cross and triangular ornaments (Figure 2 in Table 1), 
dots enclosing smaller spots (Figure 3 in Table 1), dots empty in the center (Figure 4 in Table 1) and dots as small as rice grains (Figure 5 in Table 1). However, dots of these types are less favored than the previous one.

Although widely appear, dots are seldom caught alone. They either intersperse with other patterns or form lines as edgings or frames of various kinds such as roundels, lozenges, diamonds and hexagons etc.

\section{(1) Dots intersperse with other patterns}

In this case, dots are usually used as supplementary to other patterns to add visual interest. Sometimes these dots seem to have links with other patterns [for instance the dots on a green plain woven silk fragment embroidered with a double-headed bird found in Zhagunluke (Zhao, 2005)] but sometimes do not have any relevance [for instance the dots on a red gauze piece with embroidered vines attached to the front of an vest unearthed from Huhai (Zhao, 2008)]; sometimes these dots are arranged regularly (the piece from Huahai for instance) but sometimes freely scattered (the piece from Zhagunluke for instance).

Table 2. Frames formed by linked pearls on the embroidered textiles unearthed from the Silk Road

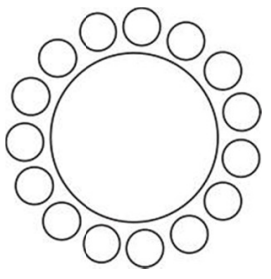

Figure 1. pearl roundel on an embroidery from Dulan or neighboring areas, late 3 thC- early 5 thC

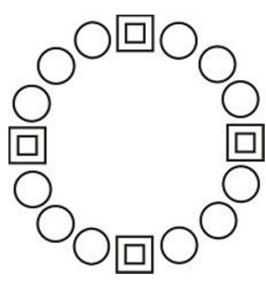

Figure 4. pearl roundel on an embroidery from Astana, 640-mid8thC

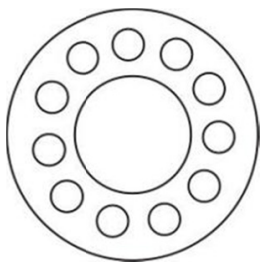

Figure 2. pearl roundel on several embroideries from Dulan or neighboring areas, late 3 thC- early 5 thC

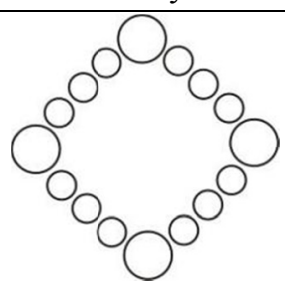

Figure 5. diamond frame on embroideries from Dulan or neighboring areas, late 3 thC- early 5 thC

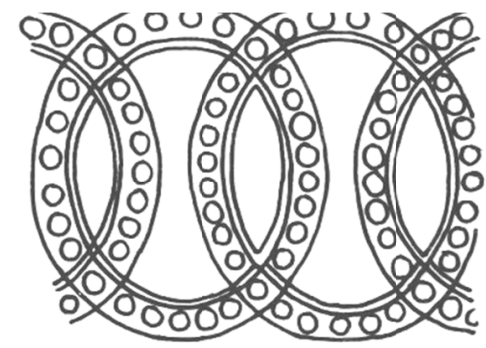

Figure 3. overlapped pearl roundels on an embroidery from Astana, 640-middle 8thC

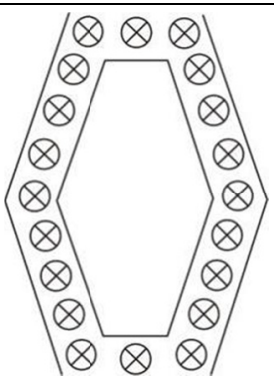

Figure 8. hexagon frame on an embroidery from Dulan or neighboring areas, late 3 thC- early 5 thC

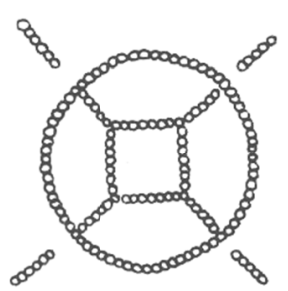

Figure 9. coin frame on two embroideries collected by Chris Hall, late 3 rdC-late 5 thC

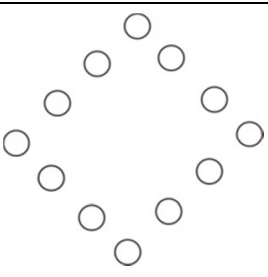

Figure 6. diamond frame on embroideries from Dulan or neighboring areas, late 3 thC- early 5 thC

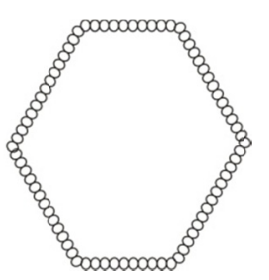

Figure 7. hexagon frame on an embroidery from the Mogao Grottoes, late 3 thC- early 5 thC

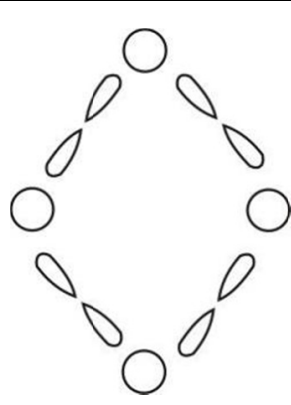

Figure 10. lozenge frame on an embroidery from

Shanpula, 2ndC BC-early 4thC AD

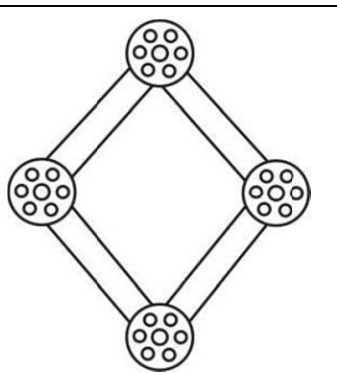

Figure 11. lozenge frame on embroideries from Dulan or neighboring areas, late 3 thC- early 5 thC

\section{(2) Dots as edgings}

Dots can be linked into straight lines and combine with other patterns to decorate the edgings of clothing or other 
articles of daily use. For example, an embroidered border from Murtuq shows linked dots in two straight lines with a strip of heart-shaped florets in between (Mokushiki, 1999); another piece from a plain woven silk garment found in Shanpula bears a line of linked dots combining with a strip of heart-shaped florets as the border (Museum of Xinjiang Uygur Autonomous Region et al, 2001). Patterns of this sort perhaps show an influence from the West, probably being an imitation of the pattern on wool tapestry.

\section{(3) Dots as frames}

Dots can also be linked into various frames then filled with other patterns. The most common example is pearl roundel (Figures 1-4 in Table 2), which is considered as a pattern originated in Sasanid Empire. Linked pearls sometimes are outlined with circles on either the inside or both the inside and outside (Figures 1-2 in Table 2). Pearl roundels outlined with circles on both sides are sometimes overlapped to form a new frame known as taohuanlianzhu in Chinese (Figure 3 in Table 2). Occasionally, the dots on the top, bottom, left and right ends of a pearl roundel are replaced by squares (Figure 4 in Table 2), which is considered to be a strong Sassanid flavor. Except for roundels, linked dots can form various geometrical frames such as diamonds (Figures 5, 6, 10 \& 11 in Table 2) and hexagons (Figures 7-8 in Table 2) or more complex frames consisting of several geometries (Figure 9 in Table 2). Generally, dots on the four corners of a diamond are different and more ornamental (Figures 5-10 $\& 11$ in Table 2).

\section{Roundels}

Roundels here refers to the pattern consists of one (Figure 1 in Table 3) or more than one (Figure 2 in Table 3 ) concentric circles enclosing grasses (Figure 1 in Table 3), florets (Figures 2-3 in Table 3) or other geometrical patterns. Sometimes, there are ornaments on the circles (Figure 3 in Table 3).Roundels filled with florets are common in this period and known as floral roundels or tuanke in Chinese (Figures 2-3 in Table 3). Floral roundels executed in embroidery are widely described in the poems of Tang dynasty (Peng Dingqiu, 1986). Roundels are mostly scattered or regularly arranged and occasionally overlapped (Figure 3 in Table 2).

Table 3. Roundels on the embroidered textiles unearthed from the Silk Road

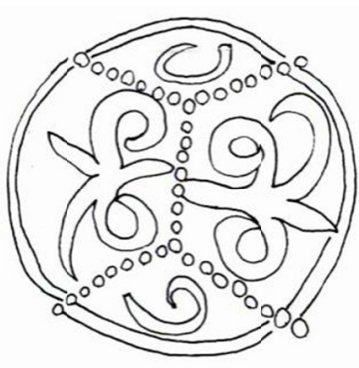

Figure 1. roundel on an embroidery from the Mogao

Grottoes, late 3 thC- early 5 thC

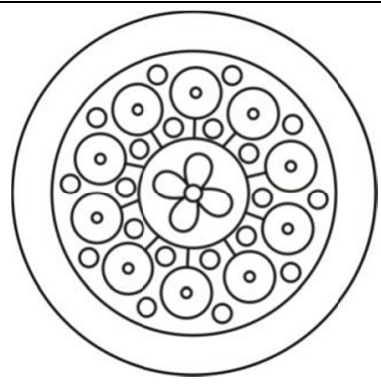

Figure 2. roundel on two embroideries from Dulan or neighboring areas, late 3 thCearly 5 thC

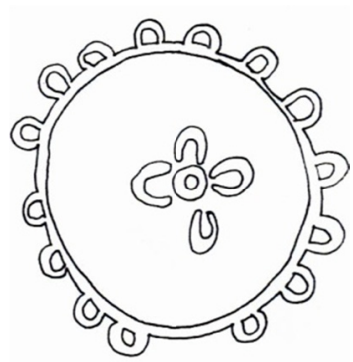

Figure 3. roundel on an embroidery from Dulan or neighboring areas, late 3 thC- early 5 thC

\section{Waves}

Waves refer to S-shaped patterns or patterns which are just like continuous waves. An example is from Dulan or neighboring areas, serving as the edgings of a square embroidered piece. It shows two S-shaped entwined waves neatly done in split stitch respectively in red and blue but both outlined in yellow. These waves are similar to ribbons. Therefore this pattern can also be identified as ribbons. (Figure 1 in Table 4) There are S-shaped frames, which are usually filled with other patterns to form a strip then decorate on the edgings of clothing or other articles of daily use. Two examples respectively from Shanpula and Dulan or neighboring areas show heart-shaped florets and half four-petalled florets filled in S-shaped frames (Figures 2-3 in Table 4).

Some patterns are not in S-shape but up and down and look like continuous waves. An example is from Cave 17 but earlier than most of the relics found in Cave 17 in dating. Neatly done stitches executed in chain stitch with silk threads in red and beige on this piece creates an effect similar to waves. It is too fragmented to reveal the pattern. However, it could possibly be part of the pattern showing mountains enveloped by clouds, which is a favored motif in the Han dynasty. (Figure 4 in Table 4) Besides, a repeat of reversed U-shaped pattern can create a similar visual effect. Two examples from Dulan or neighboring areas show reversed U-shaped patterns 
regularly respectively arranged in a line and in two rows. Patterns of this sort usually decorate on the edgings of clothing or other articles (Figures 5-6 in Table 4).

Table 4. Waves on the embroidered textiles unearthed from the Silk Road

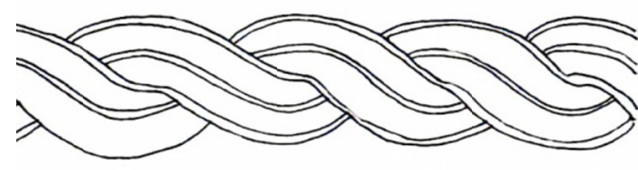

Figure 1. waves on embroideries from Dulan or neighboring areas, late 3 thC- early 5 thC

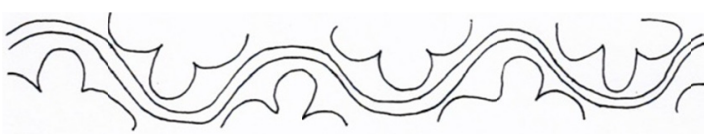

Figure 3. waves filled with half four-petalled florets on embroideries from Dulan or neighboring areas, late 3 thC- early 5 thC

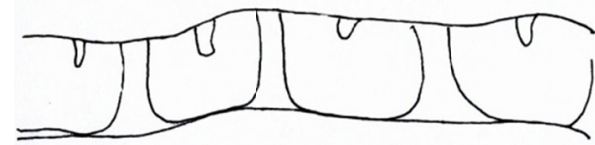

Figure 5. reversed U-shaped patterns on a embroidery from Dulan or neighboring areas, late 3 thC- early 5 thC

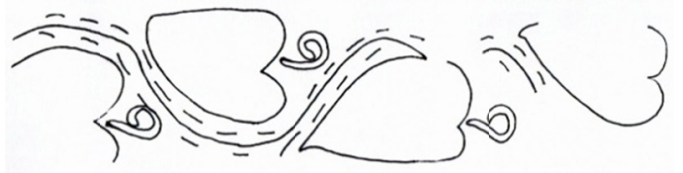

Figure 2. waves filled with heart-shaped florets on a embroidery from Shanpula, 2ndC BC-early 4thC $\mathrm{AD}$

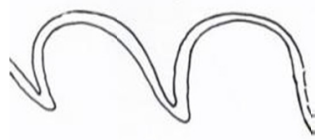

Figure 4. waves on an embroidery from cave 17 at the Mogao Grottoes, 2ndC BC -late 5thC AD

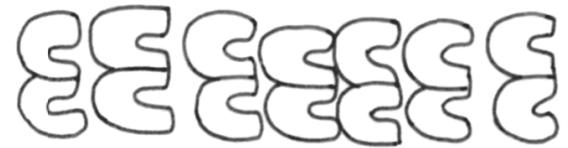

Figure 6. reversed U-shaped patterns on embroideries from Dulan or neighboring areas, late 3 thC- early 5 thC

\section{Whorls}

Whorls refer to spiral shaped patterns. There are two types of whorls according to the embroideries unearthed from the Silk Road. One is very large in scale, it is not only used as a decoration but also as a method to join textiles of different layers together (Figures 1-2 in Table 5). One is small in size, it is usually lined up and used as a decoration (Figures 3-5 in Table 5).

Table 5. Whorls on the embroidered textiles unearthed from the Silk Road

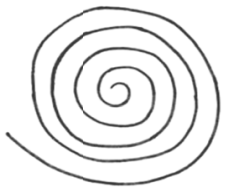

Figure 1. whorl on an embroidery from Noin-Ula, late $1 \mathrm{stC} \mathrm{BC}$-early $1 \mathrm{stC} \mathrm{AD}$

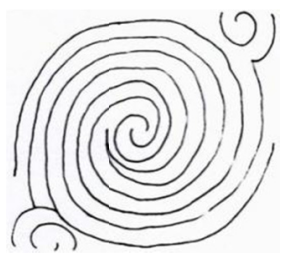

Figure 2. whorl on an embroidery from Noin-Ula, late 1stC BC-early 1stC AD

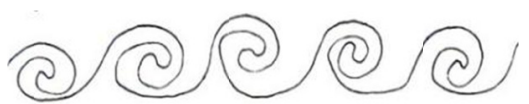

Figure 3. whorls on an embroidery from Noin-Ula, late 1 stC BC-early 1 stC AD

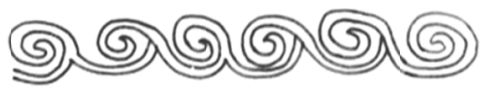

Figure 4. whorls on an embroidery from Xinjiang, 2ndC BC-early 4 thC

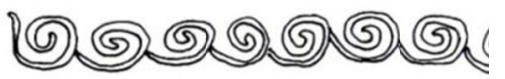

Figure 5. whorls on an embroidery from Noin-Ula, late 1 stC BC-early 1 stC AD 


\section{Triangles}

On the top of several embroideries with double-headed birds found in Astana and Zhagunluke there are a string of similar triangles. Those on the embroideries from Astana are almost identical in the shape of reversed triangles, with smaller triangles in different colors filled in the interiors and hook-shaped ornaments attached to the outside (Figures 1-2 in Table 6). Those on the embroidery from Zhagunluke are close to a valance, showing a belt on top and tiny reversed triangular pieces beneath (Figure 3 in Table 6). These triangles all appear over the heads of a double-headed bird and probably indicate zheshe, which is common on a valance or a canopy which are used over the heads of important Buddhist living beings (Kuang Yanghua, 2013a). An embroidered quilt from Noin-Ula (now in tatters) shows decorative borders consisting of triangular patterns along four edges (Figure 4 in Table 6). A similar piece was found at Mozuizi in Gansu province, showing a string of identical triangular tags each enclosing a little bird (Chen Wanxiong, 1998).

Table 6. Triangles on the embroidered textiles unearthed from the Silk Road
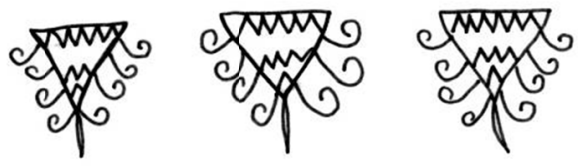

Figure 1. triangles on an embroidery from Astana, early $3 \mathrm{rdC}$ - early 4 thC

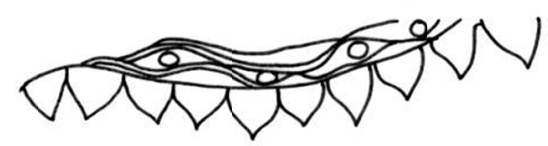

Figure 3. triangles on an embroidery from Zhagunluke, 2ndC BC-early 4thC AD
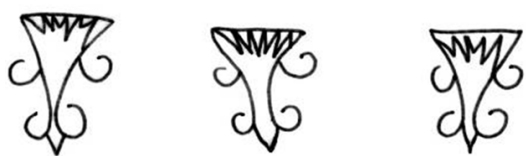

Figure 2. triangles on an embroidery from Astana, 2ndC BC-early 4thC AD

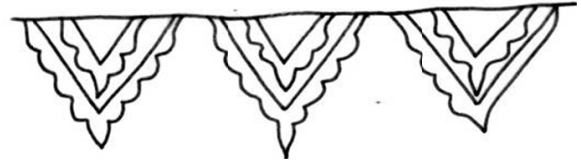

Figure 4. triangles on an embroidery from Noin-Ula, late $1 \mathrm{stC}$ BC-early $1 \mathrm{stC} \mathrm{AD}$

\section{Diamonds and Lozenges}

Table 7. Diamonds and lozenges on the embroidered textiles unearthed from the Silk Road

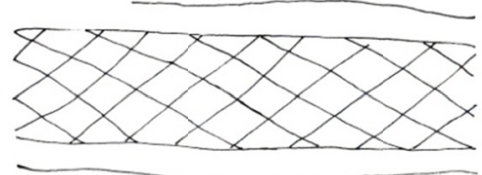

Figure 1. diamonds on embroideries from Dulan or neighboring areas, late 3 thC- early 5 thC

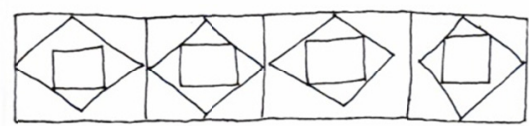

Figure 3. diamonds on embroideries from Dulan or neighboring areas, late 3 thC- early 5 thC

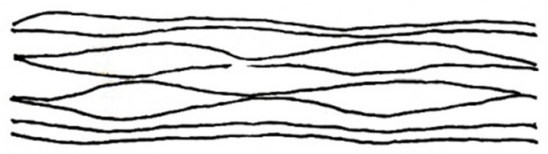

Figure 2. lozenges on an embroidery from Astana, early 3 rdC- early 4 thC

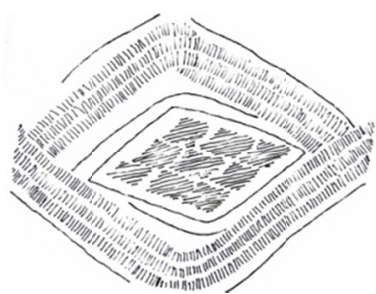

Figure 4. lozenges on an embroidery from Dulan or neighboring areas, late 3 thC- early 5 thC

Embroideries from Dulan or neighboring areas in Qinghai in the collection of China National Silk Museum show a lot of diamonds. These diamonds are usually small, being arranged in 3-5 staggered rows and used as edgings of a embroidery or frames for other patterns. Sometimes they are outlined with straight lines or curves (Figure 1 in Table 7). Similar diamonds or lozenges appear on a piece from Noin-Ula and a piece from Astana (Figure 2 in 
Table 7), however, they are large and flat. Occasionally diamonds consists of a set of triangles and even smaller diamonds (Figure 3 in Table 7).

Large lozenges can be used as alone pattern. One example is from Dulan or neighboring areas, showing large lozenges composed of small ones and outlined with concentric lozenge grids of different thickness. These lozenges are usually executed in satin stitch with strongly twisted colored silk threads (Figure 4 in Table 7).

In most cases, diamonds or lozenges are used as frames and filled with other patterns. There are a lot of examples on the embroideries from Shapula, Niya, Yinpan, Noin-Ula and Dulan or neighboring areas, showing diamonds or lozenges of different size formed by lines of different thickness (Figures $1 \& 3$ in Table 8) either arranged in a line or in staggered rows and filled with floral or geometrical patterns or occasionally used alone (Figures $5 \& 6$ in Table 8). The four corners of the diamonds or lozenges are usually embellished, for instance, with round dots (Figure 2 in Table 8), tiny diamonds (Figure 4 in Table 8), floral roundels (Figure 11 in Table 2) or geometrical rosettes (Figure 5 in Table 8 ) etc. On a piece from Noin-Ula appear concentric diamonds (Figure 6 in Table 8).

Table 8. Diamond and lozenge frames on the embroidered textiles unearthed from the Silk Road

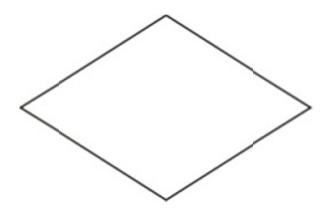

Figure 1. diamond on embroideries from Dulan or neighboring areas, late 3 thCearly 5 thC

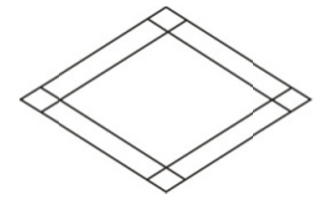

Figure 4. lozenge frame on embroideries from Dulan or neighboring areas, late 3 thCearly 5 thC

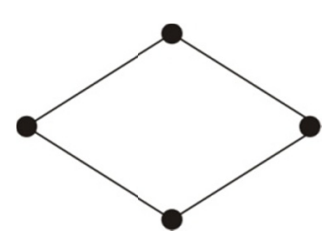

Figure 2. diamond frame on an embroidery from Shanpula, 2ndC BC-early 4thC AD

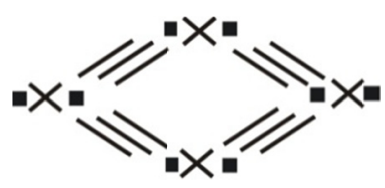

Figure 5. lozenges on embroideries in the State Hermitage Museum

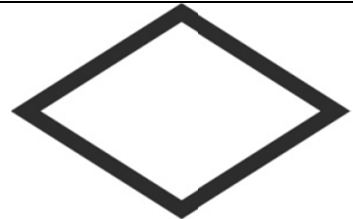

Figure 3. lozenge frame on embroideries from Dulan or neighboring areas, late 3 thCearly 5 thC

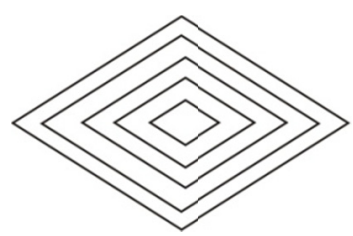

Figure 6. lozenges on an embroidery from Noin-Ula, late $1 \mathrm{stC} \mathrm{BC}$-early $1 \mathrm{stC} \mathrm{AD}$

\section{Chevrons and Zigzags}

Table 9. Chevrons and zigzags on the embroidered textiles unearthed from the Silk Road

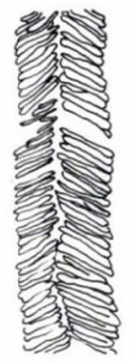

Figure 1. chevrons on embroideries from Dulan or neighboring areas, late 3 thC- early 5 thC

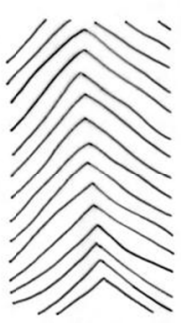

Figure 2. chevrons on an embroidery from Dulan or neighboring areas, late 3 thCearly 5 thC

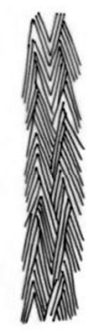

Figure 3. zigzags on an embroidery from Dulan or neighboring areas, late 3 thC- early 5 thC

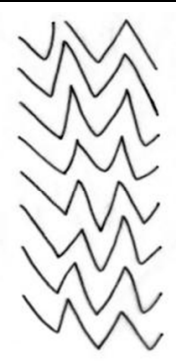

Figure 4. zigzags on an embroidery from Dulan or neighboring areas, late 3thC- early 5 thC 
Chevrons and zigzags are found on the embroideries from Dulan or neighboring areas in Qinghai in the collection of China National Silk Museum. There are two types of chevrons and zigzags: one is executed in long stitch with thick threads and closely arranged (Figures $1 \& 3$ in Table 9), the other is executed in short stitch with thin threads and loosely arranged (Figures $2 \& 4$ in Table 9). Generally, the former is adopted as frames and the latter is used as pattern filled in other frames and also as a method to join textiles of different layers together.

\section{Crosses}

It is not common to see crosses on embroideries. One example is from Niya, showing crosses enclosed in lozenges embroidered with dark brown-colored wool threads on white felt. Another example is from Dulan or neighboring areas, bearing checks each enclosing a cross embroidered with threads in beige and dark brown on a blue ground. Another piece from the same areas shows a large cross embroidered with red and blue colored threads and outlined with more crosses inside and outside. A piece from Noin-Ula also show a rectangular frame formed by alternately arranged rectangles, mushroom-shaped geometrical patterns and crosses (Sueji Umehara, 1960).

Table 10. Crosses on the embroidered textiles unearthed from the Silk Road

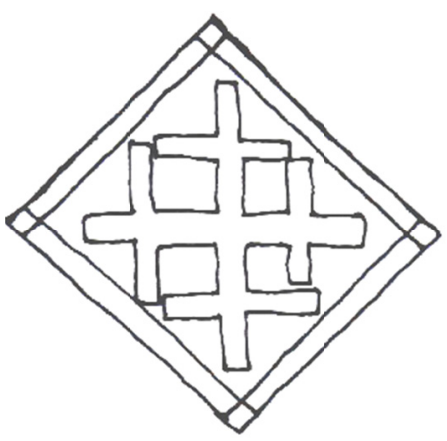

Figure 1. crosses on an embroidery from Niya, 2ndC BC-early 4 thC AD

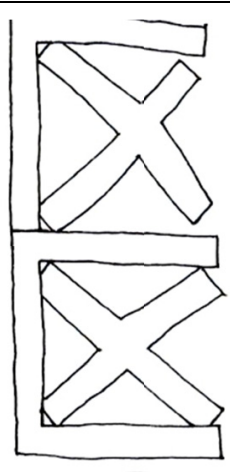

Figure 2. crosses on a embroidery from Dulan or neighboring areas, late 3 thCearly 5 thC

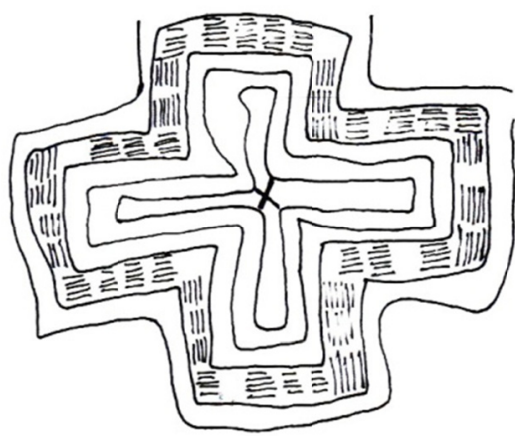

Figure 3. crosses on an embroidery from Dulan or neighboring areas, late 3 thCearly 5 thC

\section{Geometrical Patterns Consisting of More Than One Geometries}

Table 11. Examples of geometrical patterns consisting of more than one geometries on the embroidered textiles unearthed from the Silk Road

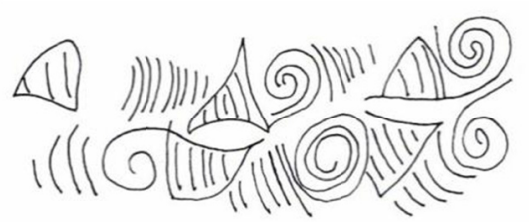

Figure 1. geometrical patterns on an embroidery from Zhagunluke, early 8thC BC-late 1stC BC

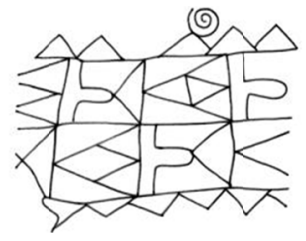

Figure 2. geometrical patterns on an embroidery from Niya, 2ndC BC-early 4thC AD

However, in some cases geometrical patterns are a result of combining more than one geometries. Take a piece from Zhagunluke and a piece from Niya for example. The unit pattern on the embroidered wool fragment from Zhagunluke is composed of three parts, two triangles at two ends and a whorl in the middle. The triangles are formed by short equidistant curves, one is outlined the other is not. The unit pattern freely repeats to from a strip of decorative pattern (Figure 1 in Table 11). Similar red-painted pattern was also found on a yellow wool textile from the same tomb (Museum of Chinese History et al, 2002). What this pattern indicates is still unknown, however, from the relics dating to the similar period found in neighboring areas, we found patterns of this sort consisting of two triangles or approximately two triangles formed by short curves with a whorl in between - is 
widely spread (Kuang, 2013b). The uppers of a pair of leather boots unearthed from Niya is decorated with colored embroidered geometrical patterns, consisting of rectangles in two rows in the middle with triangles and whorls at two sides. The rectangles are divided into several smaller geometries and according to the structure they can be classified into two groups: one is divided into a lozenge in the centre around with four triangles and one is divided into a "T"-shaped geometry, two geometries similar to trapezoid and a triangle. Rectangles of this two sorts are finally arranged in staggered rows (Figure 2 in Table 11).

\section{Conclusion}

Embroidered textiles of the Han and Tang dynasties, which are the most important archaeological evidences for the study of embroidery in the Han and Tang dynasties, are mainly found in the graveyards or ancient sites along the Silk Road in China. The evidences show that geometrical pattern is another common motif on embroidered textiles from the Silk Road, especially on the embroideries dating from the Han and Jin dynasties unearthed from Xinjiang province and the embroidered textiles of the Northern Wei dynasty from Dulan or neighboring areas in Qinghai province now in the collection of China National Silk Museum. The regular geometrical patterns on the embroidered textiles from the Silk Road include dots, roundels, waves, whorls, triangles, diamonds, lozenges, chevrons, zigzags and crosses. As the most common motif, dots not only intersperse with other patterns or form lines as edgings but also create frames of various kinds such as roundels, diamonds and hexagons etc. then filled with other patterns. Diamonds are also common, besides serving as pattern they are often used as frames. In addition, there are examples consisting of more than one type of geometrical patterns. The geometrical patterns on the embroidered textiles from the Silk Road reflects the design philosophy of the Han and Tang, especially the Han, Jin and Northern Wei dynasties, which not only promote a better understanding of pattern design in this period but also provide a helpful reference to pattern design in modern times.

\section{Acknowledgements}

This work was financially supported by the Social Science Foundation of Jiangsu Province (No. 14LSC002) and the Fundamental Research Funds for the Central Universities (No. JUSRP11469).

\section{References}

Chen, W. X. (1998). Culture of Helong: A Corridor Connecting Ancient China and the World (p. 163). Shanghai: Shanghai Far East Publishers.

Kuang, Y. H. (2013a). A Discussion on the Embroidered Textiles with Double-headed Bird Unearthed from Northwestern China. Archaeology and Cultural Relics (no. 2, pp. 90-92).

Kuang, Y. H. (2013b). Study on Embroideries of the Han and Tang Dynasties (206BC-907AD) Unearthed from the Northwest China (Dissertation) (pp. 203-204). Shanghai: Donghua University. Unpublished but available for consultation at Donghua University.

Mokushiki, K. (1999). Archaeological Findings from Northwestern China (p. 76). Beijing: Academy Press.

Museum of Chinese History \& Xinjiang Bureau of Cultural Relics. (2002). Tianshan Mountains, Ancient Roads and Influences from the East and West: A Collection of Relics Unearthed from the Silk Road (p. 123). Beijing: China Social Sciences Press.

Museum of Xinjiang Uygur Autonomous Region \& XinJiang Institute of Archaeology. (2001). Sanpula in Xinjiang of China: Revelation and Study of Ancient Khotan Civilization (p. 226). Urumqi: Xinjiang Peoples Publishing House.

Peng, D. Q. (1986). A Full Collection of Poems of the Tang Dynasty (pp. 469, 2169, 2177, 1193, 2167). Shanghai: Shanghai Classics Publishing House.

Sueji, U. (1960). Studies of Noin-Ula Finds in North Mongolia. Tokyo: The Toyo Bunko, pl.XVII.

Zhao, F. (2005). The General History of Chinese Silk (p. 165). Suzhou: Suzhou University Press.

Zhao, F. (2008). Textiles of the Han and Jin Dynasties from the Northwestern China (p. 102). Hong Kong: ISAT/Costume, Figures 4-1a, b \& 4-2a, b, c.

\section{Copyrights}

Copyright for this article is retained by the author(s), with first publication rights granted to the journal.

This is an open-access article distributed under the terms and conditions of the Creative Commons Attribution license (http://creativecommons.org/licenses/by/3.0/). 